\title{
MET amplification identified by next-generation sequencing and its clinical relevance for MET inhibitors
}

\author{
Lun-Xi Peng ${ }^{1,2+}{ }^{1}$, Guang-Ling Jie ${ }^{2,3 \dagger}{ }^{1}$, An-Na Li ${ }^{2}$, Si-Yang Liu ${ }^{2}$, Hao Sun ${ }^{2}$, Mei-Mei Zheng ${ }^{2,3}$, Jia-Ying Zhou ${ }^{2,3}$, \\ Jia-Tao Zhang 1,2, Xu-Chao Zhang 1,2, Qing Zhou 1,2, Wen-Zhao Zhong ${ }^{1,2}$, Jin-Ji Yang ${ }^{1,2}$, Hai-Yan Tu², Jian Su², \\ Hong-Hong $\mathrm{Yan}^{2}$ and Yi-Long $\mathrm{Wu}^{1,2,3^{*}}$ (])
}

\begin{abstract}
Background: MET amplification plays an important role in the development of non-small-cell lung cancer (NSCLC) either de novo or in resistance to epidermal growth factor receptor tyrosine-kinase inhibitor (EGFR-TKI) settings. Fluorescence in situ hybridization (FISH) is the standard method for MET amplification. With more and more discoveries of oncogenic driver genes, next-generation sequencing (NGS) plays a significant role in precision oncology. Meanwhile, the role of NGS in MET amplification remains uncertain.

Methods: Forty patients diagnosed with advanced NSCLC were included. FISH and NGS were conducted prior to MET inhibitors treatment. MET amplification by FISH was defined as a MET/CEP7 ratio of $>2.0$ and/or copy number (CN) > 5. MET amplification by NGS was defined as gene copy number (GCN) $\geq 5$.

Results: The concordance rate among FISH and NGS was 62.5\% (25/40). MET amplification identified by FISH showed the optimal predictive value. The partial response (PR) rate was $68.0 \%$ (17/25 with MET amplification) vs. $6.7 \%$ (1/15 without MET amplification); the median progression-free survival (PFS) was 5.4 months versus 1.0 months $(P<0.001)$. MET amplification identified by NGS failed to distinguish significant clinical outcomes. The PR rate was $60.0 \%(6 / 10$, with MET GCN $\geq 5)$ vs. $40.0 \%(12 / 30$, with MET GCN < 5); the median PFS was 4.8 months vs. 2.2 months ( $P=0.357)$. The PR rate was $68.8 \%(11 / 16)$ and the median PFS was 4.8 months in patients with focal amplification by NGS.

Conclusions: MET amplification identified by FISH remains the optimal biomarker to identify suitable candidates for MET-TKI therapy. In comparison, amplification identified by NGS seems not as robust to be effective predictive biomarker. Further exploration is needed regarding the focal amplification by NGS in predicting the efficacy.
\end{abstract}

Keywords: FISH-NGS, MET amplification, Predictive factors, Survival benefits

${ }^{*}$ Correspondence: syylwu@live.cn

${ }^{\dagger}$ Lun-Xi Peng and Guang-Ling Jie contributed equally to this work

${ }^{2}$ Guangdong Lung Cancer Institute, Guangdong Provincial Key Laboratory of Translational Medicine in Lung Cancer, Guangdong

Provincial People's Hospital \& Guangdong Academy of Medical Sciences, Guangzhou 510080, China

Full list of author information is available at the end of the article

\section{Background}

The discovery of oncogenic driver genes has improved the overall survival (OS) of advanced non-small-cell lung cancer (NSCLC) patients in clinical practice [1-4]. One of the most important achievements in NSCLC research has been the development of epidermal growth factor receptor tyrosine kinase inhibitors (EGFR-TKIs), which have increased the OS of patients with advanced-stage EGFR-mutated NSCLC to approximately 22-34 months original author(s) and the source, provide a link to the Creative Commons licence, and indicate if changes were made. The images or other third party material in this article are included in the article's Creative Commons licence, unless indicated otherwise in a credit line to the material. If material is not included in the article's Creative Commons licence and your intended use is not permitted by statutory regulation or exceeds the permitted use, you will need to obtain permission directly from the copyright holder. To view a copy of this licence, visit http://creativecommons.org/licenses/by/4.0/. The Creative Commons Public Domain Dedication waiver (http://creativeco mmons.org/publicdomain/zero/1.0/) applies to the data made available in this article, unless otherwise stated in a credit line to the data. 
[5-9]. Small molecular drugs targeting eight oncogenic driver genes (EGFR, ALK, ROS1, BRAF V600E, MET exon 14 skipping, RET, KRAS G12C, and NTRK) have been approved for the market [10]. The search for new targets has become an important direction in lung cancer research.

$M E T$, located in the 7q21-31 region, belongs to the tyrosine kinase protein family. $M E T$ activation has been shown to promote tumor cell growth, survival, migration, and invasion by interacting with multiple pathways [11]. Major types of $M E T$ abnormalities include the $M E T$ exon 14 skipping mutation, MET amplification, MET overexpression, and $M E T$ fusion. The $M E T$ exon 14 skipping mutation exists in approximately $5 \%$ of lung cancer patients and has been recognized as an oncogenic driver gene [12]. MET overexpression is common in untreated NSCLC patients, occurring in approximately $50 \%$ of this population. De novo MET amplification occurring in only $1-5 \%$ of NSCLC patients. However, among patients who develop EGFR-TKI resistance, $64 \%$ and $5-22 \%$ of patients show MET overexpression and MET amplification, respectively $[13,14]$.

$M E T$ amplification represents a resistance mechanism in EGFR-mutated NSCLC patients treated with EGFR-TKIs [15-18]. The INC280 study showed that in patients with EGFR mutation and acquired $M E T$ amplification, the combination of capmatinib with gefitinib was a promising treatment, with a disease control rate of $57 \%$. Notably, the objective response rate (ORR) was up to $47 \%$ in patients with $M E T$ amplification, defined as Copy number $(\mathrm{CN}) \geq 6$ [19]. Tepotinib plus gefitinib also showed significantly better progression-free survival (PFS) and OS than chemotherapy in patients with MET amplification (16.6 months vs. 4.2 months; 37.3 months vs. 17.9 months, respectively) [20]. Two phase Ib clinical trials revealed that a combination of savolitinib and osimertinib or gefitinib showed promising antitumor activity and tolerable toxicity in patients with acquired $M E T$-amplified NSCLC [21, 22].

Moreover, $M E T$ amplification, particularly at a high level, also seems to play a driver gene role in advanced NSCLC. A previous study showed that the ORR in groups with different MET/CEP7 ratios differed dramatically in response to the $M E T / A L K / R O S 1$ inhibitor crizotinib $(\mathrm{MET} / \mathrm{CEP7} \geq 5, \mathrm{ORR}=67 \%)$ [23]. A recent study also founded better survival benefits in patients with MET/ CEP7 $\geq 4$ (ORR of $38.1 \%$, median PFS $=6.7$ months) [24]. Presentations during the 2020 American Society of Clinical Oncology and 2020 European Society of Medical Oncology meetings reported that capmatinib had achieved higher ORR (40.0\%) and better survival benefits in patients with de novo $M E T$ amplification, especially with high-level $M E T$ amplification [gene copy number $(\mathrm{GCN}) \geq 10]$ as a first-line treatment $[25,26]$.

With respect to diagnostic modalities for MET amplification, fluorescence in situ hybridization (FISH) was considered the gold standard. A previous study showed that PFS differed significantly between patients with $M E T$ amplification-positive and -negative FISH findings (8.2 months vs. 1.3 months, $\mathrm{P}=0.002$ ) [27]. Recently, next-generation sequencing (NGS) has been widely applied in clinical practice to detect comprehensive gene profiles, including point testing of multiple-gene DNA mutations, as well as gene amplification, rearrangement, and fusion. However, the definition of $M E T$ amplification varies on different NGS platforms. The cutoff value varies from GCN 2.3-10. It remains unclear whether NGS can serve as an alternate method for identifying $M E T$ amplification. Therefore, we conducted this study to investigate the relationship between $M E T$ amplification detected by FISH and MET amplification detected by NGS. We then explored optimal biomarkers based on their efficacy in selection of suitable candidates for MET-TKI treatment in advanced NSCLC.

\section{Patients and methods}

This study was conducted at the Guangdong Lung Cancer Institute and was approved by the Research Ethics Committee of the Guangdong Provincial People's Hospital (No. 2013185H[R2]). Written informed consent was obtained from each patient prior to sample collection. From March 2014 to June 2019, 40 NSCLC patients with $M E T$ inhibitors were included in this study. Immunohistochemistry (IHC) was conducted for primary screening and then MET amplification was tested by FISH and NGS at baseline for all patients. Tumor samples were tested using FISH and NGS to identify MET amplification prior to MET-TKI. Baseline clinicopathological data, including patient characteristics and gene status (EGFR and MET), were collected from medical records. PFS was measured from the date of first administration of MET-TKIs until the date of disease progression or death. Response rate and PFS were calculated separately for FISH and NGS results, then used to compare the two methods of testing.

\section{Assessment of $M E T$ amplification Fluorescence in situ hybridization}

Dual-color FISH was performed using deparaffinized 4- $\mu$ m-thick sections with a MET/CEN7q dual-color FISH probe (Vysis, Abbott Laboratories). MET amplification was defined as a mean gene copy number $\geq 5$ and/ or MET to centromere of chromosome 7 ratio $>2.0$ and evaluated using the criteria established by Cappuzzo [22] (i.e., a mean of $>5$ copies per cell, MET-to-CEN7 ratio 
Table 1 Clinicopathologic characteristics of enrolled patients

\begin{tabular}{ll}
\hline Characteristic & N (\%) \\
\hline Age, years & \\
$<60$ & $26(65.0)$ \\
$\geq 60$ & $14(35.0)$ \\
Sex & \\
$\quad$ Female & $14(35.0)$ \\
$\quad$ Male & $26(65.0)$ \\
Pathology & \\
Adenocarcinoma & $37(92.5)$ \\
Others & $3(7.5)$ \\
EGFR status & \\
Wide-type & $21(52.5)$ \\
Mutation & $19(47.5)$ \\
MET exon 14 skipping mutations & \\
Yes & $2(5.0)$ \\
No & $38(95.0)$ \\
MET amplification by FISH & \\
Amplified & $25(62.5)$ \\
Non-amplified & $15(37.5)$ \\
MET amplification by NGS & \\
GCN $\geq 5$ & $10(25.0)$ \\
GCN <5 & $30(75.0)$ \\
Focal amplified by NGS & \\
Focal amplified & $16(40.0)$ \\
Non-focal amplified & $19(47.5)$ \\
Not available & $5(12.5)$
\end{tabular}

Data are presented as $\mathrm{n}(\%)$

GCN Gene copy number

of $>2.0$ or clustered gene amplification evident in all nuclei).

\section{Next-generation sequencing}

NGS was performed using a HiSeq 4000 NGS platform (Illumina) or NovaSeq 6000 NGS platform (Illumina). $M E T$ amplification was evaluated based on the ratio of GCN to a baseline established from a pool of samples with normal MET status. GCN $\geq 5$ was defined as MET amplification criteria from TATTON trial [22]. The criteria were samples with $\geq 10 \%$ tumor cells and $\geq 500 \times$ sequencing depth. Further analysis was conducted to distinguish between focal and non-focal MET amplification, where focal amplification was defined as a $M E T$ amplification size of < $20 \mathrm{Mbp}$ or both $M E T / C D K 6$ and $M E T / B R A F$ ratios of $\geq 1.2$.

\section{Results}

From March 2014 to June 2019, 40 NSCLC patients with $M E T$ inhibitors were included in this study. IHC was conducted for primary screening and then $M E T$ amplification was tested by FISH and NGS at baseline for all patients (Table 1). Among all tests, 25/40 cases of MET amplification were diagnosed by FISH and 10/40 cases were diagnosed by NGS (GCN $\geq 5$ ). The concordance rate between FISH and NGS was 62.5\% (25/40) (concordance rate means the same results from FISH and NGS, including negative or positive) (Fig. 1a). All patients received $M E T$ inhibitors (such as crizotinib, Savolitinib and bozitinib etc.) as treatment. The partial response (PR) rate was $45.0 \%(18 / 40)$ and the median PFS was 4.0 months (Fig. 2a).

We calculated the PR rate and PFS for MET amplification identified by FISH and NGS. In the FISH group, the PR rate was $68.0 \%(17 / 25)$ vs. $6.7 \%(1 / 15)$; the median PFS was 5.4 months vs. 1.0 months $(P<0.001)$ (Figs. $1 \mathrm{~b}, 2 \mathrm{~b})$. In the NGS group, the PR rate was $60.0 \%(6 / 10)$ vs. $40.0 \%$ (12/30); the median PFS was 4.8 months vs. 2.2 months $(P=0.357)$ (Figs. 1b, 2c). Among the 35 available tumor samples, $45.7 \%(16 / 35)$ were identified as $M E T$ focal amplification by NGS (Fig. 3). The PR rate was $68.8 \%$ (11/16) and the median PFS was 4.8 months in patients with $M E T$ focal amplification by NGS (Fig. 2d).

Multivariable analyses of PFS using the Cox proportional hazard regression method showed that PFS was significantly different only according to the $M E T$ amplification identified by FISH.

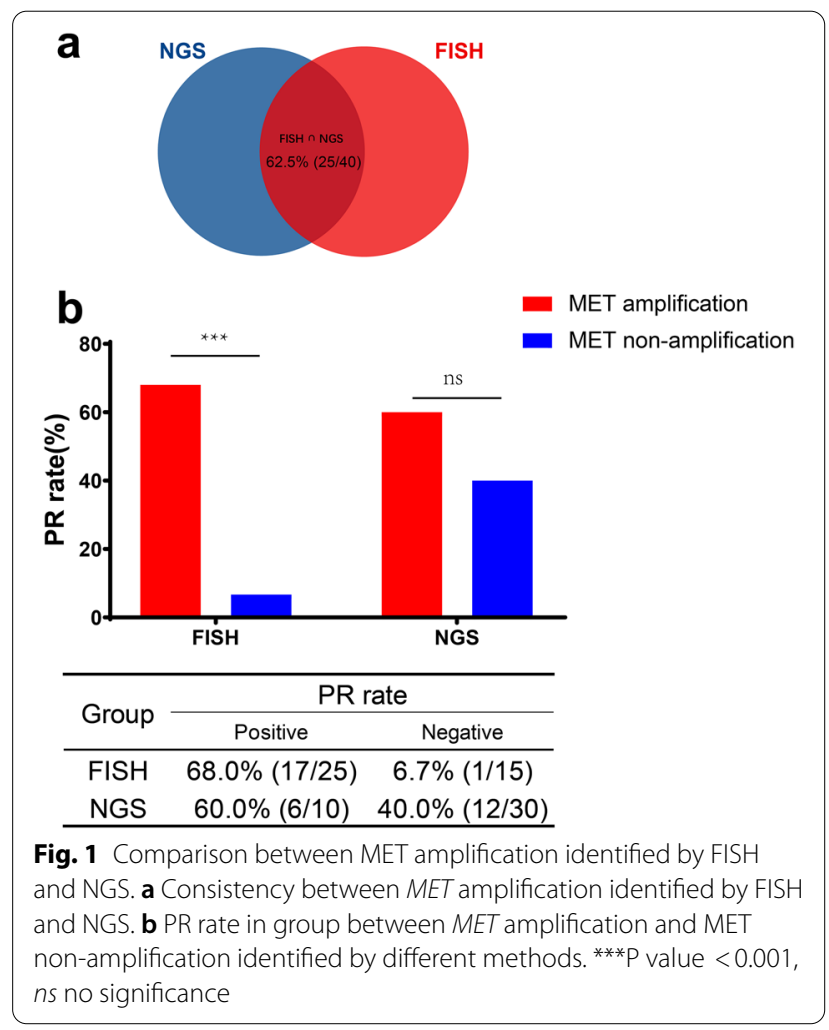




\section{Discussion}

MET amplification as a pharmaceutical target has become a hot research topic, especially in terms of EGFRTKI resistance. Unlike gene point mutation, MET amplification is difficult to test using reverse-transcription polymerase chain reaction (RT-PCR) or NGS. Although NGS results are widely used to guide the clinical management of oncogene driver-positive cancer, there is a lack of evidence regarding the accuracy and appropriateness of $M E T$ amplification identified by NGS as an indication for MET-TKI treatment. Few studies have investigated the concordance between NGS and FISH detection results for $M E T$ amplification. One study reported a low correlation of $M E T$ amplification results obtained by NGS and FISH. Among patients with FISH-positive results who had $C N \geq 8$, only $1 / 3$ exhibited $M E T$ amplification according to NGS [28]. The results of the TATTON study also showed low consistency between NGS and FISH for $M E T$ amplification. In the FISH-positive group, only $26 \%$ of the patients (12/47) were diagnosed with MET amplification by NGS $[29,30]$.
In our study, MET amplification identified by FISH showed the most optimal predictive efficiency for survival benefits. The PR rate $[68.0 \%(17 / 25)$ vs. $6.7 \%(1 / 15)]$ and the median PFS (5.4 months vs. 1.0 months) were higher in the $M E T$ amplification group than in the nonMET amplification group $(P<0.001)$. Our findings showed that FISH positivity remains as the "gold standard" for evaluating MET amplification, with high accuracy and good correlation with treatment outcomes. Several patients such as ID23, got progression although they were carrying $M E T$-amplification by FISH. It was indicating that some co-occurring gene alterations have potential to affect response, including TP53 mutation, EGFR amplification.

$M E T$ amplification identified by NGS failed to distinguish significant clinical outcomes. In the NGS group, the PR rate of $M E T$ amplification and non-amplification was $60.0 \%(6 / 10)$ vs. $40.0 \%(12 / 30)$; the median PFS was 4.8 months vs. 2.2 months $(P=0.357)$ (Fig. 2c). Moreover, setting $\mathrm{GCN}=5$ as cutoff value for MET

\section{a}

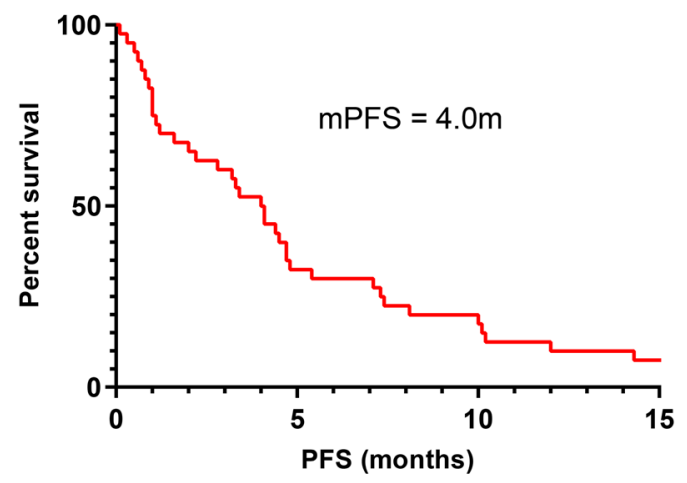

C

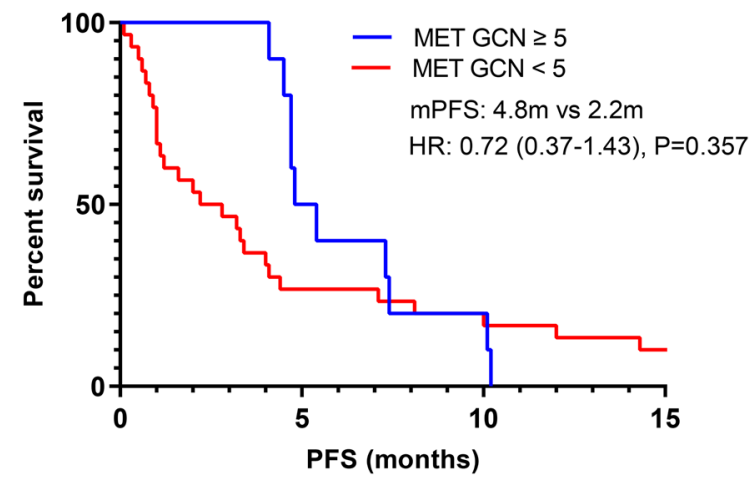

b

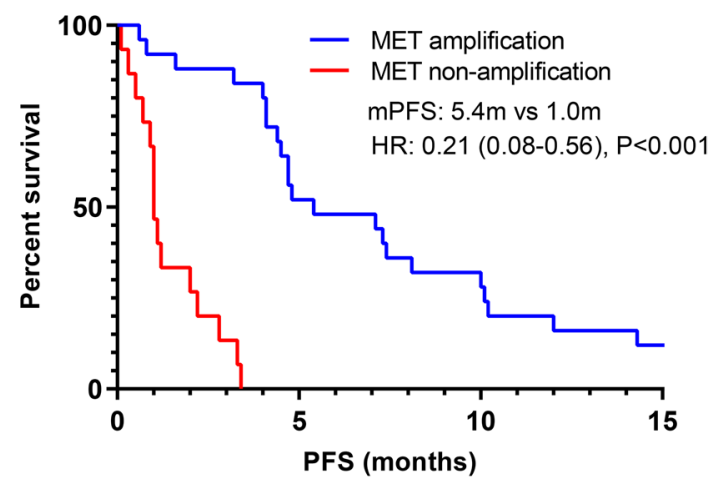

d

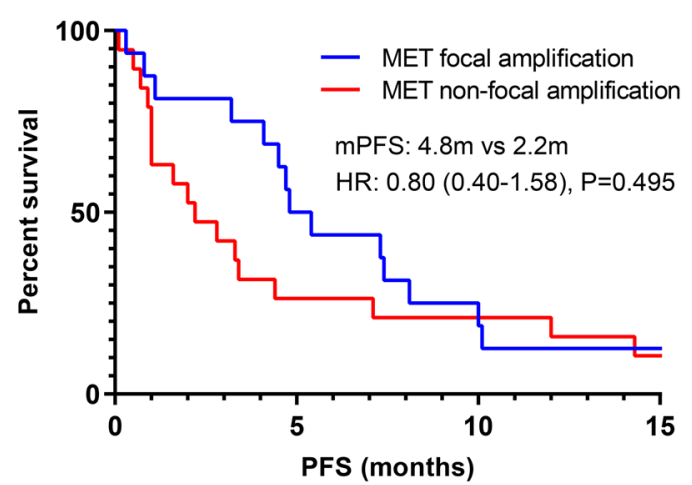

Fig. 2 Progression-free survival in patients. a Progression-free survival in all patients ( $\mathrm{n}=40$ ). b Progression-free survival between $M E T$ amplification/non-amplification by FISH $(n=40)$. c Progression-free survival between MET GCN $\geq 5 / G C N<5$ by NGS $(n=40)$. $d$ Progression-free survival between MET focal amplification/non-focal amplification by NGS ( $n=35)$ 


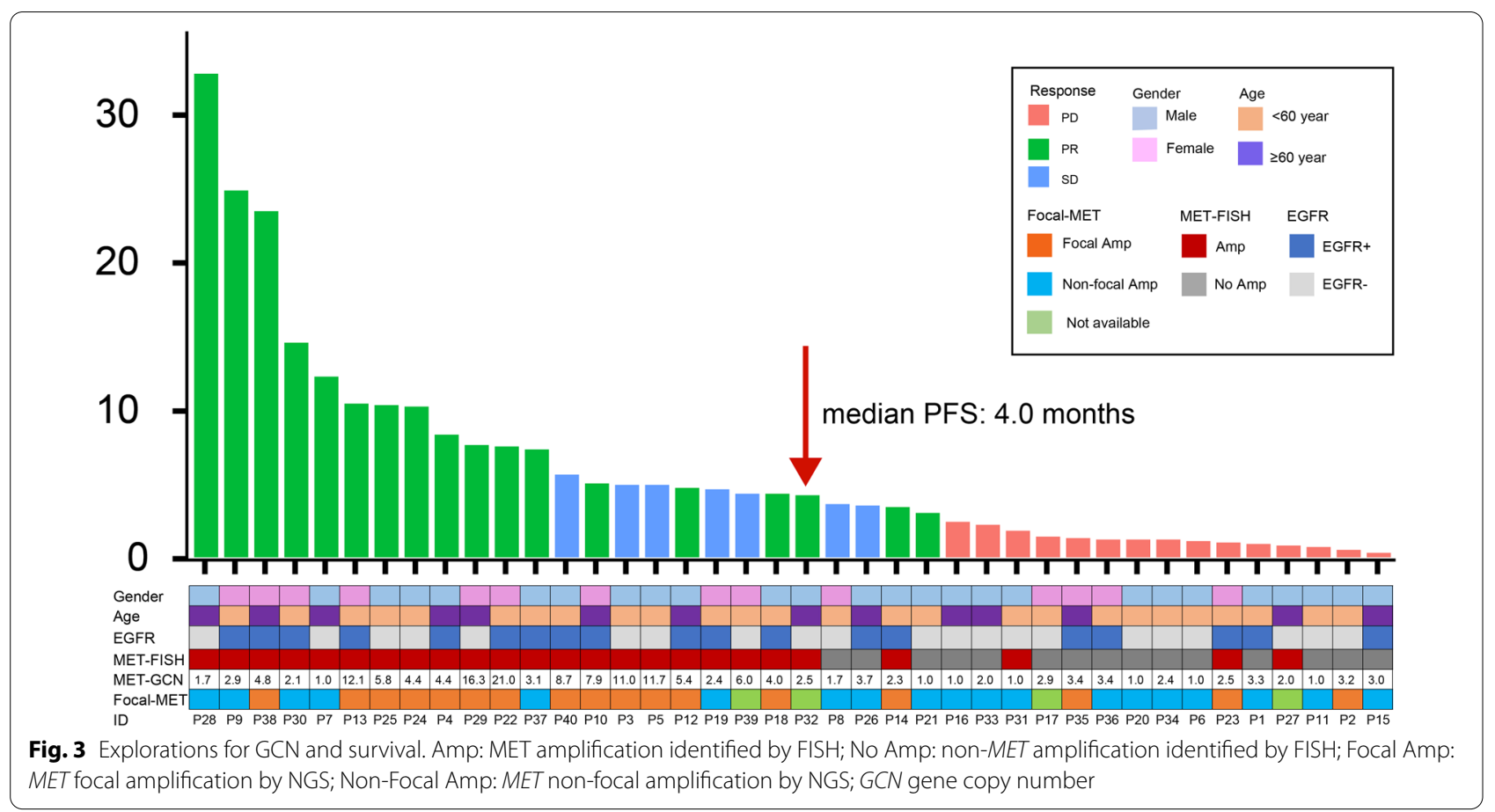

amplification by NGS was also likely to resulting in missing patients that with response.

Under FISH, MET amplification is defined as $M E T$ $\mathrm{CN}>5$ or MET/CEP7 $>2.0$. This criterion has been applied in several clinical trials including INSIGHT, VISION, and TATTON studies [19, 31-33]. Under NGS, some recent trials found higher gene copy number may have better predictive power. For example, the TATTON study defined GCN $>5$ as the $M E T$ amplification. The GEOMETRY mono-1 study also found that patients with $\mathrm{GCN} \geq 10$ tended to have a better overall response [25]. Similar results were observed in our study for patients with $\mathrm{GCN}>5$. Though only $12.5 \%(5 / 40)$ of patients showed GCN $\geq 10$, the PR rate among these patients reached $60.0 \%$, with a median PFS of 7.3 months. However, patients with lung cancer based on this criterion are rare. In our study, only $8.5 \%$ $(5 / 59)$ of patients showed a preliminary GCN of $>10$ (Additional file 1: Table S1).

We found no significant associations among $M E T$ amplification status determined by NGS with survival benefits. There remains no general consensus regarding the protocol for detecting $M E T$ amplification by NGS in patients with lung cancer. No internationally accepted standard for testing MET amplification by NGS has been established. In this study, MET amplification by NGS was based on the ratio of GCN to the baseline value from a pool of samples with a known normal MET status, such that it is difficult to discriminate true amplification and polysomy by NGS. Therefore, $M E T$ amplification testing by NGS remains uncertain and it could not be directly used in clinical practice. If GCN $<5$, it is recommended to confirm MET status by FISH (Table 1).

Biological characteristics differ between focal and non-focal $M E T$ amplification diagnosed by NGS. A previous study using hybrid-capture-based comprehensive genomic profiling showed a higher median $\mathrm{CN}$ in patients with focal $M E T$ amplification than in patients with non-focal MET amplification (11 copies vs. 7 copies; $P=0.004)$. Furthermore, neither tumor mutation burden nor co-occurring MET and EGFR mutations were significantly correlated with the size of the $M E T$ amplification. However, other co-occurring oncogenic drivers were associated with non-focal $M E T$ amplification [34]. Therefore, we explored the role of focal $M E T$ amplification using NGS. The results showed a focal MET amplification frequency of $48.5 \%$ (17/35). The PR rate was $68.8 \%(11 / 16)$ and the median PFS was 4.8 months in this patient group (Fig. 2d). Furthermore, patients with focal $M E T$ amplification present with a significantly higher median GCN than patients with non-focal MET amplification (7.5 copies vs. 2.7 copies; $P<0.001)$, suggesting that focal amplification identified by NGS and its clinical relevance warrant further research. Despite some meaningful findings obtained in this study, our small sample sizes require cautious interpretation of the results.

In conclusion, $M E T$ amplification identified by FISH remains the optimal biomarker to identify suitable candidates for MET-TKI therapy. In this small, exploratory 
series, MET amplification identified by NGS seems not as effective as a predictive biomarker for MET inhibitors. Further research is required regarding the role of focal amplification by NGS in predicting its efficacy.

\begin{abstract}
Abbreviations
EGFR: Epidermal growth factor receptor; ALK: Anaplastic lymphoma kinase; MET: Mesenchymal epithelial transition; RET: RET proto-oncogene; NTRK: Neurotrophic receptor tyrosine kinase; BRAF: B-Raf proto-oncogene; EGFR-TKl: Epidermal growth factor receptor-tyrosine kinase inhibitor; FISH: Fluorescence in situ hybridization; CN: Copy number; GCN: Gene copy number; NGS: Nextgeneration sequencing; NSCLC: Non-small cell lung cancer; ORR: Objective response rate; OS: Overall survival; PR: Partial response; PFS: Progression-free survival; RT-PCR: Reverse-transcription polymerase chain reaction.
\end{abstract}

\section{Supplementary Information}

The online version contains supplementary material available at https://doi. org/10.1186/s40164-021-00245-y.

Additional file 1: Table S1. Range of GCN of total 59 patients at the preliminary.

\section{Acknowledgements}

The study was conducted at the Guangdong Lung Cancer Institute.

\section{Authors' contributions}

YLW was responsible for the conception and design of the study, as well as for revising and approving the final manuscript. YLW, LXP, GLJ, JS, and HHY contributed to the methodology of the study. YLW, LXP, GLJ provided the conceptualization and investigation of the study. All authors contributed to the data curation of the study and review and editing of the manuscript. All authors read and approved the final manuscript.

\section{Funding}

This research was supported by the National Key R\&D Program of China (Grant Number 2016YFC1303800, to QZ), the Special Fund of Public Interest, the National Health and Family Control Committee (Grant Number 201402031, to YLW), and the Key Lab System Project of Guangdong Science and Technology Department-Guangdong Provincial Key Lab of Translational Medicine in Lung Cancer (Grant Number 2017B030314120, to YLW).

\section{Availability of data and materials}

The datasets generated and/or analyzed during the current study are not publicly available but it are available from the corresponding author on reasonable request.

\section{Declarations}

\section{Ethics approval and consent to participate}

The study was approved by the Research Ethics Committee of Guangdong Provincial People's Hospital (EC Number: 2013185H[R2]).

\section{Consent for publication}

Not applicable.

\section{Competing interests}

YLW received honoraria from AstraZeneca, Boehringer Ingelheim, BMS, Eli Lilly, Hengrui, MSD, Pfizer, Roche, and Sanofi; had a consulting or advisory role with AstraZeneca, Boehringer Ingelheim, Novartis, Merck, MSD, Roche, and Takeda; and received institutional research funding from AstraZeneca, Boehringer Ingelheim, BMS, Hengrui, Pfizer, and Roche. The authors declare that they have no competing interests.

\section{Author details}

${ }^{1}$ The Second School of Clinical Medicine, Southern Medical University, Guangzhou, China. ${ }^{2}$ Guangdong Lung Cancer Institute, Guangdong Provincial Key Laboratory of Translational Medicine in Lung Cancer, Guangdong Provincial People's Hospital \& Guangdong Academy of Medical Sciences, Guangzhou 510080, China. ${ }^{3}$ School of Medicine, South China University of Technology, Guangzhou, China.

Received: 18 September 2021 Accepted: 29 October 2021

Published online: 10 November 2021

\section{References}

1. Niu FY, Wu YL. Novel agents and strategies for overcoming EGFR TKIs resistance. Exp Hematol Oncol. 2014;3:2.

2. Fukuoka M, Wu YL, Thongprasert S, Sunpaweravong P, Leong SS, Sriuranpong $\mathrm{V}$, et al. Biomarker analyses and final overall survival results from a phase III, randomized, open-label, first-line study of gefitinib versus carboplatin/paclitaxel in clinically selected patients with advanced nonsmall-cell lung cancer in Asia (IPASS). J Clin Oncol. 2011;29:2866-74.

3. Su S, Wu YL. Clinical trials of tyrosine kinase inhibitors for lung cancer in China: a review. J Hematol Oncol. 2017;10:147.

4. Huang L, Jiang S, Shi Y. Tyrosine kinase inhibitors for solid tumors in the past 20 years (2001-2020). Exp Hematol Oncol. 2020;13:143.

5. Lee CK, Davies L, Wu YL, Mitsudomi T, Inoue A, Rosell R, et al. Gefitinib or erlotinib vs chemotherapy for EGFR mutation-positive lung cancer: individual patient data meta-analysis of overall survival. J Natl Cancer Inst. 2017. https://doi.org/10.1093/jnci/djw279.

6. Gao G, Ren S, Li A, Xu J, Xu Q, Su C, et al. Epidermal growth factor receptor-tyrosine kinase inhibitor therapy is effective as first-line treatment of advanced non-small-cell lung cancer with mutated EGFR: a meta-analysis from six phase III randomized controlled trials. Int J Cancer. 2012;131:E822-9.

7. Zhang C, Leighl NB, Wu YL, Zhong WZ. Emerging therapies for non-small cell lung cancer. J Hematol Oncol. 2019;12:45.

8. Zhou C, Wu YL, Chen G, Feng J, Liu XQ, Wang C, et al. Final overall survival results from a randomised, phase III study of erlotinib versus chemotherapy as first-line treatment of EGFR mutation-positive advanced non-small-cell lung cancer (OPTIMAL, CTONG-0802). Ann Oncol. 2015;26:1877-83.

9. Mok TS, Cheng Y, Zhou X, Lee KH, Nakagawa K, Niho S, et al. Improvement in overall survival in a randomized study that compared dacomitinib with gefitinib in patients with advanced non-small-cell lung cancer and EGFRactivating mutations. J Clin Oncol. 2018;36:2244-50.

10. Chen R, Manochakian R, James L, Azzouqa AG, Shi H, Zhang Y, et al. Emerging therapeutic agents for advanced non-small cell lung cancer. J Hematol Oncol. 2020;13:58.

11. Trusolino L, Bertotti A, Comoglio PM. MET signalling: principles and functions in development, organ regeneration and cancer. Nat Rev Mol Cell Biol. 2010;11:834-48.

12. Dziadziuszko R, Wynes MW, Singh S, Asuncion BR, Ranger-Moore J, Konopa K, et al. Correlation between MET gene copy number by silver in situ hybridization and protein expression by immunohistochemistry in non-small cell lung cancer. J Thorac Oncol. 2012;7:340-7.

13. Schildhaus HU, Schultheis AM, Ruschoff J, Binot E, Merkelbach-Bruse S, Fassunke J, et al. MET amplification status in therapy-naive adeno- and squamous cell carcinomas of the lung. Clin Cancer Res. 2015;21:907-15.

14. Park S, Choi YL, Sung CO, An J, Seo J, Ahn MJ, et al. High MET copy number and MET overexpression: poor outcome in non-small cell lung cancer patients. Histol Histopathol. 2012;27:197-207.

15. Engelman JA, Zejnullahu K, Mitsudomi T, Song Y, Hyland C, Park JO, et al. MET amplification leads to gefitinib resistance in lung cancer by activating ERBB3 signaling. Science. 2007;316:1039-43.

16. Turke AB, Zejnullahu $K, W u Y L$, Song $Y$, Dias-Santagata $D$, Lifshits $E$, et al. Preexistence and clonal selection of MET amplification in EGFR mutant NSCLC. Cancer Cell. 2010;17:77-88.

17. Ou S-HI, Agarwal N, Ali SM. High MET amplification level as a resistance mechanism to osimertinib (AZD9291) in a patient that symptomatically responded to crizotinib treatment post-osimertinib progression. Lung Cancer. 2016;98:59-61. 
18. Wang $Q$, Yang $S$, Wang $K$, Sun SY. MET inhibitors for targeted therapy of EGFRTKI-resistant lung cancer. J Hematol Oncol. 2019;12:63.

19. Wu YL, Zhang L, Kim DW, Liu X, Lee DH, Yang JC, et al. Phase Ib/II study of capmatinib (INC280) plus gefitinib after failure of epidermal growth factor receptor (EGFR) inhibitor therapy in patients with EGFR-mutated, MET factor-dysregulated non-small-cell lung cancer. J Clin Oncol. 2018;36:3101-9.

20. Wu YL, Cheng Y, Zhou J, Lu S, Zhang Y, Zhao J, et al. Tepotinib plus gefitinib in patients with EGFR-mutant non-small-cell lung cancer with MET overexpression or MET amplification and acquired resistance to previous EGFR inhibitor (INSIGHT study): an open-label, phase 1b/2, multicentre, randomised trial. Lancet Respir Med. 2020;8:1132-43.

21. Yang J, Fang J, Shu Y, Chang J, Chen G, He J, et al. OA 09.06 A phase Ib trial of savolitinib plus gefitinib for Chinese patients with EGFR-mutant METamplified advanced NSCLC. J Thorac Oncol. 2017;12:S1769.

22. Sequist LV, Han JY, Ahn MJ, Cho BC, Yu H, Kim SW, et al. Osimertinib plus savolitinib in patients with EGFR mutation-positive, MET-amplified, non-small-cell lung cancer after progression on EGFR tyrosine kinase inhibitors: interim results from a multicentre, open-label, phase $1 \mathrm{~b}$ study. Lancet Oncol. 2020:21:373-86.

23. Camidge DR, Ou S-HI, Shapiro G, Otterson GA, Villaruz LC, Villalona-Calero $M A$, et al. Efficacy and safety of crizotinib in patients with advanced c-MET-amplified non-small cell lung cancer (NSCLC). J Clin Oncol. 2014;32:8001

24. Camidge DR, Otterson GA, Clark JW, Ignatius Ou SH, Weiss J, Ades S, et al. Crizotinib in patients with MET-amplified NSCLC. J Thorac Oncol. 2021;16:1017-29.

25. Wolf J, Overbeck TR, Han J-Y, Hochmair M, de Marinis F, Ohashi K, et al. Capmatinib in patients with high-level MET-amplified advanced nonsmall cell lung cancer (NSCLC): results from the phase 2 GEOMETRY mono-1 study. J Clin Oncol. 2020:38:9509.

26. Wolf J, Seto T, Han JY, Reguart N, Garon EB, Groen HJM, et al. Results of the GEOMETRY mono-1 phase II study for evaluation of the MET inhibitor capmatinib (INC280) in patients (pts) with METAex14 mutated advanced non-small cell lung cancer (NSCLC). Ann Oncol. 2018;29:viii741-2.

27. Li A, Yang J, Zhang X, Su J, Zhou Q, Chen H, et al. P1.01-018 acquired resistance to crizotinib in advanced NSCLC with de novo MET overexpression. J Thorac Oncol. 2017;12:S1899.
28. Lai GGY, Lim TH, Lim J, Liew PJR, Kwang XL, Nahar R, et al. Clonal MET amplification as a determinant of tyrosine kinase inhibitor resistance in epidermal growth factor receptor-mutant non-small-cell lung cancer. J Clin Oncol. 2019;37:876-84.

29. Sequist LV, Lee JS, Han J-Y, Su W-C, Yang JC-H, Yu H, et al. Abstract CT033: TATTON phase Ib expansion cohort: osimertinib plus savolitinib for patients (pts) with EGFR-mutant, MET-amplified NSCLC after progression on prior third-generation epidermal growth factor receptor (EGFR) tyrosine kinase inhibitor (TKI). Cancer Res. 2019;79:CT033-CT.

30. Yu H, Ahn M-J, Kim S-W, Cho BC, Sequist L, Orlov S, et al. Abstract CT032: TATTON Phase Ib expansion cohort: osimertinib plus savolitinib for patients (pts) with EGFR-mutant, MET-amplified NSCLC after progression on prior first/second-generation epidermal growth factor receptor (EGFR) tyrosine kinase inhibitor (TKI). Cancer Res. 2019;79:CT02-CT.

31. Song Z, Wang H, Yu Z, Lu P, Xu C, Chen G, et al. De novo MET amplification in chinese patients with non-small-cell lung cancer and treatment efficacy with crizotinib: a multicenter retrospective study. Clin Lung Cancer. 2019;20:e171-6.

32. Noonan SA, Berry L, Lu X, Gao D, Baron AE, Chesnut P, et al. Identifying the appropriate FISH criteria for defining MET copy number-driven lung adenocarcinoma through oncogene overlap analysis. J Thorac Oncol. 2016;11:1293-304.

33. Cheng Y, Zhou J, Lu S, Zhang Y, Zhao J, Pan H, et al. Phase II study of tepotinib + gefitinib (TEP+GEF) in MET-positive (MET+)/epidermal growth factor receptor (EGFR)-mutant (MT) non-small cell lung cancer (NSCLC). Ann Oncol. 2018;29:viii493-547.

34. Ou S, Pavlick D, Stephens PJ, Ross J, Miller V, Ali S, et al. OA 12.08 genomic analysis of non-small cell lung cancer (NSCLC) cases with focal and nonfocal MET amplification. J Thorac Oncol. 2017;12:S1778-9.

\section{Publisher's Note}

Springer Nature remains neutral with regard to jurisdictional claims in published maps and institutional affiliations.

Ready to submit your research? Choose BMC and benefit from:

- fast, convenient online submission

- thorough peer review by experienced researchers in your field

- rapid publication on acceptance

- support for research data, including large and complex data types

- gold Open Access which fosters wider collaboration and increased citations

- maximum visibility for your research: over $100 \mathrm{M}$ website views per year

At BMC, research is always in progress.

Learn more biomedcentral.com/submissions 